\title{
Pharmaceutical Care Made Easy
}

\section{John Sexton, Gareth Nickless and Chris Green, Pharmaceutical Press, London, 2006, £19.95, ISBN 0-85369-650-0}

\author{
J. W. F. van Mil
}

Received: 15 January 2007/ Accepted: 15 January 2007/Published online: 3 August 2007

(C) Springer Science+Business Media B.V. 2007

How easy can pharmaceutical care be? In spite of its title, this book does not make it easy at all. The book is cramped with information and clearly written to support problembased learning. Additionally, the frequently used abbreviations used make it difficult for reading.

As a good start, in the introductions, the authors explain what they consider pharmaceutical care to be. There is a very good chapter on prioritising drug-related problems (or pharmaceutical care issues, whatever you prefer). Further in the book the problems areas are presented, like cardiology, respiratory medicine, endocrinology and rheumatology, nephrology and renal transplantation, gastroenterology, neurology and psychiatry, surgical and general problem, and pharmaceutical problems. The most frequent pathologies in these fields are discussed, with a reference to optimal treatment and the treatment problems that possibly need attention.
I may be getting old, but in my view, much of the information presented in this book belongs in old-fashioned standard books and broad lectures on pathology and clinical pharmacology. Although the book is a very good attempt to bring together essential information about diseases and medicine use from the pharmaceutical care viewpoint, the book also proves that the material simply is too complex for self-study for undergraduate students. There is a whole world of knowledge that one must acquire before this book can be used.

The book therefore is very useful for practicing pharmacists who want to refresh and test their knowledge and it can also be used for problem based learning in the continuing education setting.
J. W. F. van Mil (ه)

Margrietlaan 1, Zuidlaren 9471 CT, The Netherlands

e-mail: jwfvmil@planet.nl 